\title{
Contextual Constraints in Media Choice: Beyond Information Richness
}

By: Prashant Palvia, Praveen Pinjani, Sherrie Cannoy and Tim Jacks

Palvia, P., Pinjani, P., Cannoy, S.D., and Jacks, T. "Contextual Constraints in Media Choice: Beyond Information Richness”. Decision Support Systems. Vol. 51(3), 2011, pp. 657-670

Made available courtesy of Elsevier:

http://www.sciencedirect.com/science/article/pii/S0167923611000984

***Reprinted with permission. No further reproduction is authorized without written permission from Elsevier. This version of the document is not the version of record. Figures and/or pictures may be missing from this format of the document. $* * *$

\begin{abstract}
:
In today's dynamic environment, managers and organizations are faced with varied choices in communicating information for enhanced decision making. In business, the selection of the appropriate media needs to be efficient and effective for decision making and can be crucial in certain circumstances. Recent studies have relied on numerous theories to explain media choice. This research work goes beyond the traditional task characteristics of equivocality and uncertainty from the media richness theory. It addresses additional contextual constraints including the needs for urgency, confidentiality, accountability, social interaction, and information integrity from the sender's perspective and how these interact with equivocality and uncertainty in the choice of a medium for communication. Results demonstrate a significant change in media selection under all five contextual constraints, although not always in the direction predicted. Email was consistently the top preference, contrary to theoretical expectations. The study adds empirical support to the growing trend of moving beyond media and information richness in order to explain media choice in organizations.
\end{abstract}

Keywords: information richness | media choice | contextual constraints | confidentiality | urgency | accountability | social interaction | information integrity

\section{Article:}

1. Introduction

Organizations today face more severe competition and economic pressures compared to a few decades ago. Challenges include new and effective ways to conserve resources, reduce costs, and be agile in responding to consumers and customers, and constantly adopt new information technologies including the Internet. Also emerging in the face of global expansion is the geographical dispersion of the firm from local boundaries to international markets. In this wake, organizations have witnessed changing patterns of organizational structures from simple hierarchy to distributed forms. To support the communication requirements of such large and 
multi-faceted organizations, advances in computer-mediated communication (CMC) are being explored and developed by organizations. The use of different media for inter and intra organizational communication can increase the productivity and efficiency of individual managers and the organization as a whole [6]. Understanding how and why different communication media, computer-mediated or otherwise, are used in organizations becomes essential to prescribe and to predict sound rationale organizational investments in different media choices.

Managers dedicate a substantial amount of time to communicate in order to carry out their assigned responsibilities and work in a cohesive group environment. Research has shown that as high as seventy-five percent of a manager's time is spent in communication-related activities [26]. While communication activities are composed of numerous tasks, including both sending and receiving communication, one that is of great importance from an organizational perspective is the media selection itself. The rapid growth in the use of Email and other forms of CMC leads to questions about the circumstances under which people use these media for information exchange. Organizational and institutional decision makers want to know how computer media can aid the information exchange process, what kinds of information are best delivered through which media, and why people use one medium over another.

The topic of media selection is not new to the Information Systems (IS) literature. Many studies have been conducted to assess and analyze media selection factors and patterns. Previous research on media selection has been primarily motivated by two predominant theories: social presence theory [13] and media richness theory [6]. Both theories focus on the determinants of media choice and posit that the match between the medium and task results in effective communication. The underlying tenet of these theories is that media choice is dependent upon the characteristics of media and each communication medium is unique in its ability to convey certain information content. Media richness theory, in particular, explains how high performing managers match media with the appropriate amount of information richness to the characteristics of a task [6]. Although social presence theory and media richness theory have provided an appealing conceptual framework and have stimulated a stream of research, subsequent empirical tests have not provided consistent results [22] and [25]. Additional research on media selection has been categorized by social influence theory [12] and channel expansion theory [2], which highlights the notion of selection of media beyond the traditional task-media fit.

The ever increasing reliance of organizations on electronic media for communications, the ubiquitous use of email, and advances in communication technologies have significantly contributed to the continued interest and research in the area of media selection and choice. To keep up with the emerging and powerful changes, scholars have proposed several alternate 
theories to understand the media selection phenomenon, as described in the next section. With the advent of "smartphones" and the mobile media landscape, new issues and opportunities have emerged which warrant further research and new insights into media selection and move beyond the traditional task-technology fit realm and focus more on context driven media selection.

This study goes beyond the concept of information richness in communication media to explore the broader area of context. This research is aimed at highlighting and understanding the significance of context and the constraints it implies on media selection. We propose that medium choice is affected by two distinct groups of variables: 1) task characteristics and 2) contextual constraints. Task characteristics are the traditional two from media richness theory: equivocality and uncertainty. In addition, five likely contextual constraints include: 1) need for urgency, 2) need for social interaction, 3) need for confidentiality, 4) need for information integrity, and 5) need for accountability. The main research question is: do contextual constraints significantly affect media choice over and above the traditional task characteristics of equivocality and uncertainty? An auxiliary research question is: does media richness theory have effective predictive power over media selection in organizations?

The paper is organized as follows. First, we review the literature on media choice in the context of task by focusing on media richness theory, social presence theory, and related empirical findings. Second, we develop a set of hypotheses regarding the effect of factors beyond media richness and present the research model. Third, we present the research methodology and discuss

results from the data analysis. Finally, we discuss the key findings along with limitations and suggestions for further research.

\section{Literature review}

During the last two decades, substantial research effort has been aimed at identifying factors that shape manager's selection of communication media. Initial research efforts in understanding media selection were based on Information Richness Theory (IRT) [6] and [7] which ranks information media along the single dimension of richness and proposed a match between task characteristics and the communication channel. The information conveyed in a face to face conversation is considered "richer" than a conversation over Email due to two main characteristics: feedback and cues. A face to face conversation can include immediate feedback to the sender when the receiver asks clarifying questions. In addition, body language can provide non-verbal cues for whether the information is being transmitted successfully or not. These elements are not present in "lean" communication media such as Email. Information richness and media richness are sometimes used interchangeably in the literature. While they do overlap a 
great deal, Otondo et al. [28] observe that there are two distinct types of richness: the richness of information and the richness of the medium carrying the information. Media richness is a medium's capacity to process rich information and information richness is the ability of a message to change understanding within a time interval. Table 1 lists a few of the most significant research articles based on media/information richness and media choice.

Table 1. Sample articles from literature review.

\begin{tabular}{|c|c|c|c|}
\hline Author & Title & Journal & Methodology \\
\hline Daft and Lengel [6] & $\begin{array}{l}\text { Organizational information requirements, } \\
\text { media richness and structural design }\end{array}$ & MS & Descriptive \\
\hline $\begin{array}{l}\text { Daft, Lengel and } \\
\text { Trevino [7] }\end{array}$ & $\begin{array}{l}\text { Message equivocality, media selection, and } \\
\text { manager performance: implications for } \\
\text { information systems }\end{array}$ & MISQ & Field study \\
\hline $\begin{array}{l}\text { Zmud, Lind and } \\
\text { Young [49] }\end{array}$ & $\begin{array}{l}\text { An attribute space for organizational } \\
\text { communication channels }\end{array}$ & ISR & Survey \\
\hline Lee (1994) [22] & $\begin{array}{l}\text { Electronic mail as a medium for rich } \\
\text { communication: an empirical investigation } \\
\text { usinghermeneutic interpretation }\end{array}$ & MISQ & Case study \\
\hline King and Xia [19] & $\begin{array}{l}\text { Media appropriateness: effects of experience } \\
\text { on communication choice media choice }\end{array}$ & DS & $\begin{array}{l}\text { Longitudinal study } \\
\text { — quasi experiment }\end{array}$ \\
\hline Dennis and Kinney[9] & $\begin{array}{l}\text { Testing media richness theory in the new } \\
\text { media: the effects of cues, feedback, and task } \\
\text { equivocality }\end{array}$ & ISR & Experiment \\
\hline Carlson and Davis [1] & $\begin{array}{l}\text { An investigation of media selection among } \\
\text { directors and managers: from "self" to "other" } \\
\text { orientation }\end{array}$ & MISQ & $\begin{array}{l}\text { Case study; } \\
\text { interviews }\end{array}$ \\
\hline $\begin{array}{l}\text { Straub and } \\
\text { Karahanna [38] }\end{array}$ & $\begin{array}{l}\text { Knowledge worker communications and } \\
\text { recipient availability: toward a task closure } \\
\text { explanation of media choice }\end{array}$ & OS & Survey \\
\hline $\begin{array}{l}\text { Sussman and Sproull } \\
\text { [39] }\end{array}$ & $\begin{array}{l}\text { Straight talk: delivering bad news through } \\
\text { electronic communication }\end{array}$ & ISR & Lab experiment \\
\hline $\begin{array}{l}\text { Otondo, Van Scotter, } \\
\text { Allen and Palvia [28] }\end{array}$ & $\begin{array}{l}\text { The complexity of richness: media, message, } \\
\text { and communication outcomes }\end{array}$ & I\&M & Experiment \\
\hline $\begin{array}{l}\text { Watson-Manheim and } \\
\text { Belanger [47] }\end{array}$ & $\begin{array}{l}\text { Communication media repertoires: dealing } \\
\text { with the multiplicity of media choices }\end{array}$ & MISQ & Multiple case study \\
\hline
\end{tabular}




\begin{tabular}{l|l|l|l|l|l|l|l}
\hline Author & Title & Journal & Methodology \\
\hline $\begin{array}{l}\text { Dennis, Fuller and } \\
\text { Valacich [10] }\end{array}$ & $\begin{array}{l}\text { Media, tasks, and communication processes: a } \\
\text { theory of media synchronicity }\end{array}$ & MISQ & Theory and review \\
\hline $\begin{array}{l}\text { Chen, Yen, Hung and } \\
\text { Huang [5] }\end{array}$ & $\begin{array}{l}\text { An exploratory study of the selection of } \\
\text { communication media: the relationship } \\
\text { between flow and communication outcomes }\end{array}$ & DSS & Experiment \\
\hline $\begin{array}{l}\text { Lee, Kozar and Larsen } \\
\text { [23] }\end{array}$ & $\begin{array}{l}\text { Avatar e-mail versus traditional e-mail: } \\
\text { perceptual difference and media selection } \\
\text { difference }\end{array}$ & DSS & Field study \\
\hline $\begin{array}{l}\text { Johnson and Cooper } \\
\text { [17] }\end{array}$ & $\begin{array}{l}\text { Media, affect, concession, and agreement in } \\
\text { negotiation: IM versus telephone }\end{array}$ & DSS & Experiment \\
\hline $\begin{array}{l}\text { Thatcher and Brown } \\
\text { [41] }\end{array}$ & $\begin{array}{l}\text { Individual creativity in teams: the importance } \\
\text { of communication media mix }\end{array}$ & DSS & Field study \\
\hline
\end{tabular}

In later years, media richness theory (MRT) was the subject of numerous evaluations, some resulting in its disconfirmation [25] and [31], whereas others suggesting modifications to the theory [7] and [34]. MRT has generally been supported when tested on traditional media, but inconsistent results have been found with regard to new CMCs [25]. For example, even though email is generally regarded as a lean medium, its ability to convey rich information has been demonstrated in the literature [22] and [25]. At the same time, different media can be employed to varying degrees of success for issues related to politics, power, and control [25] and [33]. Playfulness can be a factor in media selection [5] and media selection can impact creativity [41]. MRT has also been lacking in explaining symbolic cues of the media [42], social environment [31], user experience [2], media synchronicity [9], and context [4]. These inconsistencies have encouraged a reconsideration of the MRT resulting in an emergence of theories based on social context to explain media selection [12] and [13].

The social presence theory explains media selection behavior of workers in a group environment, and factors like beliefs of peers and superiors are expected to partially determine managerial media selection [12]. Social presence refers to how much a particular medium allows communicators to experience other people as being psychologically present [19]. Different communication tasks require different levels of social presence and different media provide greater or lesser amounts of social presence [19] and [23]. For example, face to face communication can provide more social presence than Email. Just as there should be a good fit between the task requirements for richness in selecting a particular medium, so should there be a good fit for the task requirements for social presence. 
More recent attempts to understand media selection have focused on social contexts. Carlson and Davis [2] have looked at media selection from the perspective of organizational roles. They concluded that directors in an organization are more "self" oriented in their media choice, more often choosing media based on access and ease of use criteria, while managers were more "other" oriented, more often making choices based on media richness, and social presence criteria. Shachaf and Hara [36], in their case study on media selection by Global Virtual Teams concluded that media choice is a process of elimination, excluding channels and limiting channel repertoire to fit the particular situation. This process is affected by six contingencies: physical proximity, task at hand, social proximity, sender and receiver accessibility of a channel, individual preferences about a channel, and the initial channel. Finally, Johnson and Cooper [17] conducted an experiment to find that CMC can reduce the amount of affect communicated and thereby negatively impact negotiation outcomes.

Some other researchers have taken a completely different perspective on explaining media choice. Notable among these approaches is the channel expansion theory [2] which identifies certain experiences as important in shaping how an individual develops richness perceptions for a given channel. Most recently, the Media Synchronicity Theory is a promising successor to media richness theory [10]. Media Synchronicity Theory holds that there are two aspects to communication: conveyance and convergence. Proper medium selection comes only when the information transmission and processing needs of the communication process are in sync with the information transmission and processing capabilities of the medium itself.

From the literature, there are a large amount of inconsistencies that point to the fact that media choice may not be adequately explained or predicted by considering only the inherent richness of information or social presence of the medium and task characteristics. Also evident from the literature analysis is the absence of factors like confidentiality and accountability, which are of paramount importance in communication in present day organizations. The most recent research has also indicated a need to go beyond information and media richness to address media synchronicity [10]. It is evident that task characteristics alone do not explain media choice. This paper seeks to go beyond information richness of the medium and the characteristics of the task to explore the context of communication, i.e., how the traditional task characteristics of equivocality and uncertainty interact with contextual factors such as need for urgency, need for social interaction, need for confidentiality, need for information integrity, and need for accountability in media selection. 


\section{Research model}

We propose that media choice is influenced by two sets of forces: task characteristics and contextual constraints. These are discussed next, including the related hypotheses, and how the hypotheses fit into the larger research model.

\subsection{Task factors}

Researchers have theorized and empirically validated that task characteristics affect the media that individuals select for communication purposes. Daft and Lengel [6], in their seminal work on media richness, argued that managers can improve performance by matching media characteristics to the needs of the organizational information processing tasks. Task was characterized based on two variables, uncertainty and equivocality.

Uncertainty is conceptualized as the absence of information [6]. It is defined as "the difference between the amount of information required to perform a task and the amount of information already possessed by the individual” [6]. Individuals respond to uncertainty by collecting and analyzing data to gather information. For the purpose of collection and gathering information, managers rely on communication media available at their disposal. Thus uncertainty, as dictated by a task, affects the media choice made by an individual.

Equivocality is defined as ambiguity, the existence of multiple and conflicting interpretations about an organizational task [6]. Equivocality has also been conceptualized as meaning confusion, disagreement and lack of understanding. Media selection has been postulated to be influenced by equivocality reduction and, under situations with high equivocality, communicators understand and interpret existing information differently [6]. The purpose of communication in such situations is to integrate these different interpretations and establish common meaning.

Specific tasks being faced by managers can be classified based on the level of uncertainty and equivocality inherent in the task. Media richness theory holds that these tasks characteristics can be addressed if appropriate media is selected for communication. Available media were characterized based on their level of richness in terms of media cues, immediacy of feedback, language and personal focus of the media [6]. Various studies have examined different numbers of communication channels, both electronic and non-electronic [6], [19] and [27]. This study 
examines the most popular channels based on predominance in the literature. These are: 1) Faceto-face, 2) Instant Messaging, 3) Telephone, 4) Email, 5) Letter/Memo, and 6) Fax.

Based on the interaction of the two task characteristics and arguments in the literature cited earlier, we make the following predictive hypotheses:

H1

. Tasks involving high equivocality and high uncertainty will lead to selection of a very rich medium for communication purposes, such as face-to-face.

$\mathrm{H} 2$

. Tasks involving high equivocality and low uncertainty will lead to selection of a less rich medium for communication purposes, such as instant messaging and telephone.

H3

. Tasks involving low equivocality and high uncertainty will lead to selection of a more lean medium for communication purposes, such as Email.

H4

. Tasks involving low equivocality and low uncertainty will lead to selection of a very lean medium for communication purposes, such as letter/memo or fax.

\subsection{Contextual constraints}

In addition to the task/medium fit, there may be certain contextual constraints imposed on the sender of the communication which also influence the media selection for a particular task. These contextual constraints may significantly alter the choice of media beyond the task/medium fit. The selection of contextual constraints is derived from existing literature. Table 2 highlights the references for contextual constraints.

Table 2. Contextual constraints from the literature. 


\begin{tabular}{l|l|l|l|l|l|l|l|l}
$\begin{array}{l}\text { Contextual } \\
\text { constraint }\end{array}$ & Definition & Reference \\
$\begin{array}{l}\text { Need for urgency } \\
\text { (immediacy of } \\
\text { feedback) }\end{array}$ & $\begin{array}{l}\text { Is the extent to which a receiver requires a rapid } \\
\text { feedback on the communications they send }\end{array}$ & [6],[18] and [49] \\
\hline $\begin{array}{l}\text { Need for social } \\
\text { interaction }\end{array}$ & $\begin{array}{l}\text { Set of communicative processes outside of } \\
\text { information exchange, in which people reach } \\
\text { out to others in patently social ways to enable } \\
\text { information exchange }\end{array}$ & [18], [27],[37] and [38] \\
\hline $\begin{array}{l}\text { Need for } \\
\text { confidentiality }\end{array}$ & $\begin{array}{l}\text { Not releasing or disclosing information to } \\
\text { unauthorized individuals, entities or processes }\end{array}$ & [11] \\
\hline $\begin{array}{l}\text { Need for } \\
\text { information } \\
\text { integrity }\end{array}$ & $\begin{array}{l}\text { The state that exists when computerized data are } \\
\text { the same as those in the source documents and } \\
\text { have not been exposed to accidental or }\end{array}$ & [3] \\
\hline malicious alteration or destruction & \\
\hline $\begin{array}{l}\text { Need for } \\
\text { accountability }\end{array}$ & $\begin{array}{l}\text { The quality or state which enables } \\
\text { communication to be traced to individuals who } \\
\text { may then be held responsible }\end{array}$ & \\
\hline
\end{tabular}

\subsubsection{Need for urgency}

There are many references to urgency in the media selection literature (e.g., [9], [40], [42], [43], [47] and [49]). Need for urgency is defined as "is the extent to which a receiver requires a rapid feedback on the communications they send”. A message is urgent when a quick response is needed [47]. The need for urgency in the situation of the task may be an important determinant of the type of medium selected. More urgent communications should prompt communicators to select a medium that possesses real time, synchronous response capabilities. Real-time response capabilities of a medium have been conceptualized as immediacy of feedback [6]. Walther [45] concluded that time is an important factor in determining the degree to which a particular media is used for interpersonal communication. Thus, the hypothesis: 
. All other things being equal, a high need for task-related urgency will lead to the selection of a medium capable of delivering the communication urgently, such as face-to-face or phone, and be significantly different than the medium selection based on the match of task characteristics of equivocality and uncertainty alone.

\subsubsection{Need for social interaction}

The need for social interaction, defined as, a "set of communicative processes outside of information exchange, in which people reach out to others in patently social ways to enable information exchange" [27], also called 'outeraction', may have a significant influence on media selection. Not only do organizational members have informal work ties, they also have friendships at work that may be independent of their work ties. The intimacy of coworkers' friendships can range between levels such as being work colleagues only, being acquaintances, friends, or close friends. Members of an organization may seek to enhance their social ties with every opportunity available. Inherent in the need for accomplishing an organizational task may be the need for social interaction. Social presence theory explains that people will select a communication medium that has an appropriate amount of social presence. This presumes that social interaction itself is seen as potentially valuable.

Media can be characterized, on the basis of perceptions of individuals about sociability of media. Different types of media can be perceived by individuals to be ranging from a highly sociable media, capable of improving work and friendship ties, to media with low level of sociable capability, not aiding social interaction in any way. Kishi [21] refers to the importance of social factors in media selection such as work group norms, collective rules, and social utility and Kahai and Cooper [18] refer to the importance of the socio-emotional climate where supportive and friendly conditions may reduce inhibitions, but neither addresses the possible interaction of a need for social interaction itself with equivocality and uncertainty. Thus,

H6

. All other things being equal, a high need for social interaction will lead to the selection of a medium with high social presence, such as face-to-face, and be significantly different than the medium selection based on the match of task characteristics of equivocality and uncertainty alone.

3.2.3. Need for confidentiality 
Confidentiality has been defined as "not releasing or disclosing information to unauthorized individuals, entities or processes” [11]. In the present day business environment where information possesses the ability to deliver competitive advantage [30], it becomes imperative in many cases that information confidentiality related to the task be of paramount importance. Furthermore, new technologies for communication have increased the vulnerability of information to be possessed by unauthorized users on the Internet. Zmud et al. [49] previously addressed confidentiality as part of their construct on "accessibility” of media but did not examine its relationship with equivocality and uncertainty.

The need for confidentiality may be an important factor that determines the selection of a particular type of media. Different media can be categorized as secure and non-secure media based on the perceptions communicators have towards these media. Thus,

H7

. All other things being equal, a high need for task-related confidentiality will lead to the selection of a medium perceived to be secure from the sender's perspective, such as face-to-face, and be significantly different than the medium selection based on the match of task characteristics of equivocality and uncertainty alone.

\subsubsection{Need for information integrity}

Information integrity has been defined as "the state that exists when computerized data are the same as those in the source documents and have not been exposed to accidental or malicious alteration or destruction" [3]. Although this definition is in the context of computerized data, it applies equally to other forms of communication. Task characteristics in interaction with need for information integrity may influence media selection by organizational members. Zmud et al. [49] previously addressed unreliability and inaccuracy as part of their construct on "quality" of media but did not examine its relationship with equivocality and uncertainty. Accordingly,

H8

. All other things being equal, a high need for task-related information integrity will lead to the selection of a medium perceived to be capable of maintaining high levels of information 
integrity, such as letter or memo, and be significantly different than the medium selection based on the match of task characteristics of equivocality and uncertainty alone.

\title{
3.2.5. Need for accountability
}

Accountability has been defined as "the quality or state which enables communication to be traced to individuals who may then be held responsible" [44]. Need for accountability by individuals who wish to be responsible for the task may select media which supports an audit trail of communication and this information is readily available. Such media would possess the capability to trace information back to the sender, as opposed to media which do not provide this facility. Thus,

H9

\begin{abstract}
. All other things being equal, a high need for individual and task-related accountability will lead to the selection of a medium perceived to provide more accountability from the sender's perspective, such as Email, and be significantly different than the medium selection based on the match of task characteristics of equivocality and uncertainty alone.
\end{abstract}

Fig. 1 depicts the research model with media choice as the dependent variable and both task and contextual constraints as two separate forces influencing media choice by organizational members. 


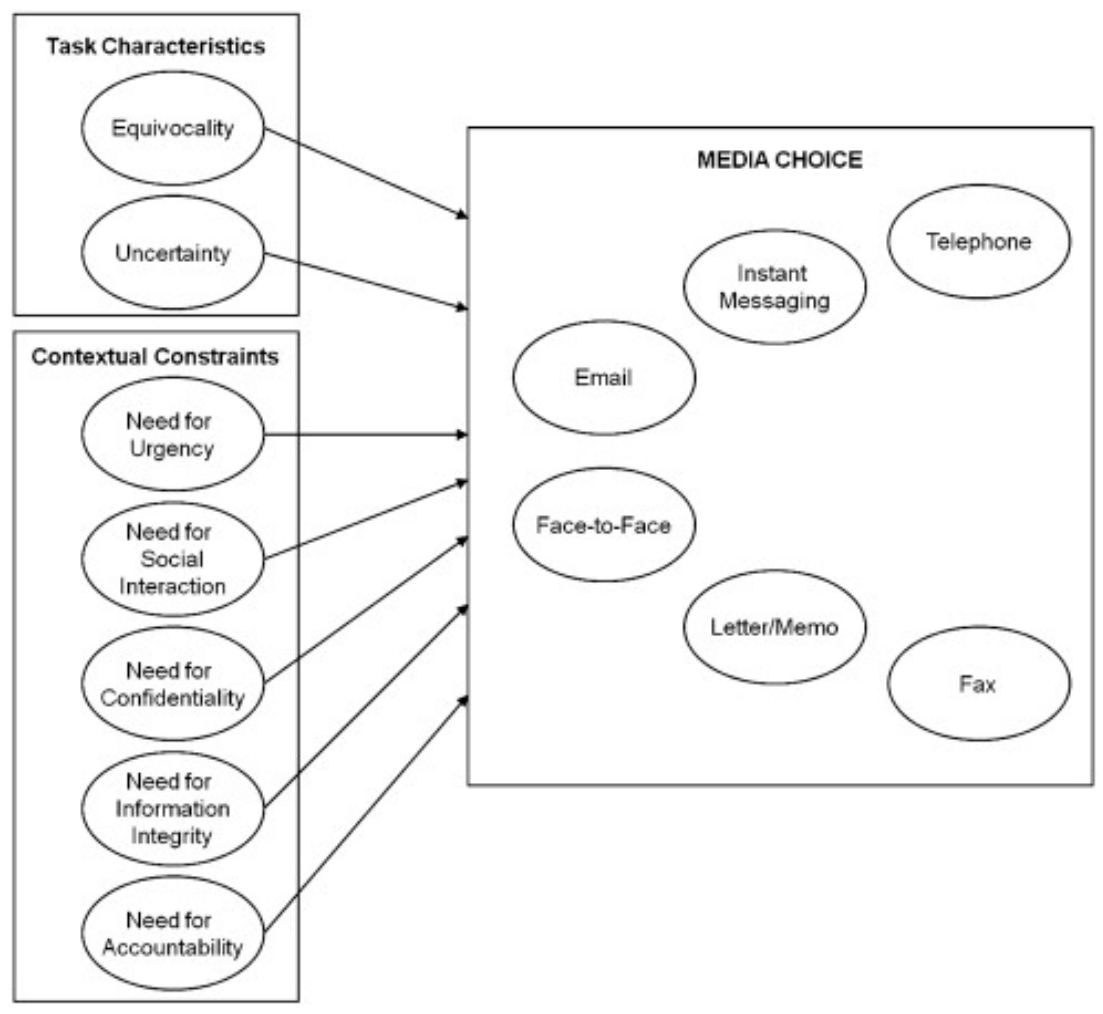

Fig. 1. The research model.

\section{Research method}

A scenario-based survey methodology was utilized. The full list of questions from the instrument can be found in the Appendix. The scenarios were adapted from Straub and Karahanna [38] and had been previously validated. The scenarios were business-based hypothetical situations that were appropriate for the population of interest. An example of a scenario would be the following:

There has been disagreement about how to proceed with the implementation of a new information security policy and you need to resolve the issue with your project group of 10 members.

\subsection{Variables}

Seven independent variables were measured in the research model: two variables representing task characteristics (uncertainty and equivocality) and five variables representing the five contextual constraints, namely 1) need for urgency, 2) need for social interaction, 3) need for confidentiality, 4) need for information integrity, and 5) need for accountability. Because the impacts of uncertainty and equivocality have been investigated in past research, this study uses 
these two factors as the base and evaluates the impact of the five contextual constraints on media choice superimposed on four base scenarios of uncertainty and equivocality. These four scenarios represented the four combinations of high and low values of uncertainty and equivocality. The dependent variable: media choice, included the most widely used choices from the literature and included Email, fax, telephone, face-to-face communication, written letters and memos, and Instant Messaging (IM) [6], [19] and [27].

\subsection{Base scenarios of uncertainty and equivocality}

A pre-pilot study was conducted to determine the base scenarios of equivocality and uncertainty upon which all of the other scenarios would be based. Eight scenarios, varying in the levels of uncertainty and equivocality, were constructed based on the literature and administered to a group of doctoral students. The objective was to determine appropriate task scenarios representing the four combinations of high and low uncertainty and high and low equivocality (i.e., high equivocality and low uncertainty HELU, high equivocality and high uncertainty HEHU, low equivocality and low uncertainty LELU, low equivocality and high uncertainty LEHU.) Respondents were requested to assess the level of equivocality and uncertainty on a five-point Likert scale ranging from high to low. Table 3 shows the results from the pre-pilot where four best scenarios were selected from the eight possible. Task 8 seemed a little vague to the respondents, so the wording was changed to ensure a more concise interpretation of Low Equivocality and High Uncertainty. Some minor changes were made to the manner in which the demographic information was worded. The four base scenarios are displayed in Table 4.

Table 3. Pre-pilot results.

1-5 scale with 1 being low and 5 being high Categories of task feature

\begin{tabular}{|c|c|c|c|}
\hline Task & Equivocality & Uncertainty & \\
\hline Task 2 & 4.43 & 2.29 & HE, LU \\
\hline Task 6 & 4.43 & 4.00 & $\mathrm{HE}, \mathrm{HU}$ \\
\hline Task 7 & 1.00 & 1.86 & LE, LU \\
\hline Task 8 & 2.14 & 3.57 & LE, LU \\
\hline
\end{tabular}


Table 4. Four base scenarios.

$\begin{array}{ll}\text { Task } & \text { Scenario description } \\ \text { characteristics } & \end{array}$

HELU There has been disagreement about how to proceed with the implementation of a new information security policy and you need to resolve the issue with your project group of 10 members.

HEHU You need to contact colleagues from the 20 departments in your company to discuss the variance in the sales of several of your major product lines. The sales have fluctuated rapidly and seemingly without a pattern.

LELU You want to gather the birth date (month and day) of the five colleagues in your department.

LEHU

You want to gather an extensive set of standard sales figures from the 40 regional managers in your organization.

Note that the number of participants in the base scenarios is not the same. This was to some extent purposeful to create different levels of equivocality and uncertainty. For example, in HE scenarios, in order to convey high ambiguity, multiple interpretations, and confusion, the number of communication participants is 10 and 20. In LELU scenarios, the number of communication participants is small, but LEHU had higher number of participants in order to increase uncertainty to an otherwise simple task. In any case, the pre-pilot study validated the base scenarios.

\subsection{Instrument}

In order to create the scenarios showing the interaction of the four base scenarios with the five contextual constraints, additional wording was added to each scenario. For example, to measure the interaction of "need for social interaction", the statement "you have worked closely with this group in the past and enjoy their company" was added to each of the four core scenarios. This resulted in 44 distinct scenarios for the survey. (Five constraints that were either high or low became ten possibilities multiplied by the four core scenarios equals 40 , plus the original four, which equaled a total of 44 distinct scenarios.) The survey questions were phrased such that the respondent could choose only one medium that they thought was best for each given scenario. The Appendix provides a complete list of the scenarios. 


\subsection{Pilot study}

The scenarios were randomized for the pilot study, which were administered to a class of undergraduate students in a Business Processing course in the Business School of a southeastern U.S. university. The sample consisted of 37 respondents who were given extra credit points as a motivation to answer the survey scenarios diligently. Students did not ask for clarification of any of the scenarios or demographic items, and the instruments were filled out as expected with few problems in the manner they were completed. Therefore, the scenarios needed only minor modifications for the full study.

\subsection{Full study}

The full-scale study was administered to Master's level business classes at the southeastern U.S. University. Note that it is acceptable to use student surrogates, especially Master's students many of whom are working in real world jobs, for professional users [20]. In addition to measuring the impact of the variables, demographic information was collected as well as some questions were included to measure the perceptions of these media. These perceptions were gathered to corroborate commonly held perceptions of media characteristics.

\section{Results and analysis}

\subsection{Demographics}

There were a total of 83 respondents. Of these, 54 were males, 27 were females, and two did not report their gender. The average age was 28.7 and the educational level was split almost evenly between first year and second year Master's students (and one doctoral student). With 65\% of the respondents being employed, on average, they had worked 7.02 years. Note that the unit of analysis is at the individual level.

\subsection{Perceived media characteristics}

As shown in Table 5, the most readily available medium with the least amount of inconvenience was Email, followed by phone, letter, and face-to-face ranked with decreasing availability. Faceto-face communication was thought to be the most secure (providing background for H7), with phone communication a close second. The least secure communications were instant messaging and fax. Feedback and cues are two important elements of media richness. The most immediate feedback according to the respondents is from face-to-face, with telephone and instant messaging 
following in order. Letters were found to be the most delayed type of communication. The medium providing most cues was face-to-face communication, with telephone and instant messaging following in order. Letters and fax ranked the lowest in providing media cues, just behind Email. Feedback and cues provided background for H1, H2, H3 and H4. As expected, face-to-face communication was found to be the most sociable media choice, providing background for H6. Telephone and instant messaging were thought to be fairly sociable, with Email, fax, and letter as somewhat sociable.

Table 5. Rankings of media based on characteristics.

Rankings based on frequency counts of highest ratings

\begin{tabular}{|c|c|c|c|c|c|c|}
\hline Media characteristics & $1 \mathrm{st}$ & 2nd & 3rd & 4th & 5th & 6th \\
\hline $\begin{array}{l}\text { Comfort Level-\% that } \\
\text { rated the media as } \\
\text { levels 3-5 (comfortable } \\
\text { to very comfortable) }\end{array}$ & $\begin{array}{l}\text { Email } \\
(100 \%)\end{array}$ & $\begin{array}{l}\text { Phone } \\
(97.6 \%)\end{array}$ & $\begin{array}{l}\text { Face-to- } \\
\text { face } \\
(96.8 \%)\end{array}$ & $\begin{array}{l}\text { Letter } \\
(91.6 \%)\end{array}$ & $\begin{array}{l}\text { Fax } \\
\text { (85.5\%) }\end{array}$ & $\begin{array}{l}\text { Instant } \\
\text { messaging } \\
(80.7 \%)\end{array}$ \\
\hline $\begin{array}{l}\text { Availability-\% that } \\
\text { rated the media as } \\
\text { levels 3-5 (available } \\
\text { with some } \\
\text { inconvenience to } \\
\text { readily available) }\end{array}$ & $\begin{array}{l}\text { Email } \\
(100 \%)\end{array}$ & $\begin{array}{l}\text { Phone } \\
(98.7 \%)\end{array}$ & $\begin{array}{l}\text { Face-to- } \\
\text { face } \\
(98.7 \%)\end{array}$ & $\begin{array}{l}\text { Letter } \\
(96.2 \%)\end{array}$ & $\begin{array}{l}\text { Fax } \\
(74.7 \%)\end{array}$ & $\begin{array}{l}\text { Instant } \\
\text { messaging } \\
(68 \%)\end{array}$ \\
\hline $\begin{array}{l}\text { Security-\% that rated } \\
\text { the media as levels 3-5 } \\
\text { (somewhat secure to } \\
\text { very secure) }\end{array}$ & $\begin{array}{l}\text { Face-to- } \\
\text { face } \\
(92.8 \%)\end{array}$ & $\begin{array}{l}\text { Phone } \\
\text { (83.1\%) }\end{array}$ & $\begin{array}{l}\text { Letter } \\
\text { (83.1\%) }\end{array}$ & $\begin{array}{l}\text { Email } \\
(61.4 \%)\end{array}$ & $\begin{array}{l}\text { Instant } \\
\text { messaging } \\
(55.6 \%)\end{array}$ & $\begin{array}{l}\text { Fax } \\
(55.6 \%)\end{array}$ \\
\hline $\begin{array}{l}\text { Feedback Immediacy-\% } \\
\text { that rated the media as } \\
\text { levels 3-5 (immediate } \\
\text { to very immediate) }\end{array}$ & $\begin{array}{l}\text { Face-to- } \\
\text { face } \\
(98.8 \%)\end{array}$ & $\begin{array}{l}\text { Phone } \\
(95.2 \%)\end{array}$ & $\begin{array}{l}\text { Instant } \\
\text { messaging } \\
(93.7 \%)\end{array}$ & $\begin{array}{l}\text { Email } \\
(60.2 \%)\end{array}$ & $\begin{array}{l}\text { Fax } \\
(30.1 \%)\end{array}$ & $\begin{array}{l}\text { Letter } \\
(10.8 \%)\end{array}$ \\
\hline $\begin{array}{l}\text { Media Cues-\% that } \\
\text { rated the amount of } \\
\text { cues as levels } 3-5 \\
\text { (some cues to a large } \\
\text { amount of cues) }\end{array}$ & $\begin{array}{l}\text { Face-to- } \\
\text { face } \\
(98.8 \%)\end{array}$ & $\begin{array}{l}\text { Phone } \\
(90.4 \%)\end{array}$ & $\begin{array}{l}\text { Instant } \\
\text { messaging } \\
(53.1 \%)\end{array}$ & $\begin{array}{l}\text { Email } \\
(45.8 \%)\end{array}$ & $\begin{array}{l}\text { Letter } \\
\text { (38.6\%) }\end{array}$ & $\begin{array}{l}\text { Fax } \\
(22.9 \%)\end{array}$ \\
\hline $\begin{array}{l}\text { Media Sociability-\% } \\
\text { that rated the media at } \\
\text { levels 3-5 (sociable to }\end{array}$ & $\begin{array}{l}\text { Face-to- } \\
\text { face } \\
(100.0 \%)\end{array}$ & $\begin{array}{l}\text { Phone } \\
(98.8 \%)\end{array}$ & $\begin{array}{l}\text { Instant } \\
\text { messaging } \\
(80.0 \%)\end{array}$ & $\begin{array}{l}\text { Email } \\
(62.7 \%)\end{array}$ & $\begin{array}{l}\text { Letter } \\
\text { (48.2\%) }\end{array}$ & Fax (6\%) \\
\hline
\end{tabular}


Rankings based on frequency counts of highest ratings

\begin{tabular}{|l|l|l|l|l|l|}
\hline Media characteristics & 1 st & 2nd & 3rd & 4 th & th \\
\hline very sociable) & & &
\end{tabular}

\subsection{Media choice: base cases}

Table 6 shows the results of media choices based solely on the task characteristics of equivocality and uncertainty without any contextual constraints. The results do not support H1, that tasks involving high equivocality and high uncertainty would lead to selection of a very rich medium like face-to-face. On the contrary, Email, a very lean medium, was chosen by $51.8 \%$ of the respondents. The very rich medium of face-to-face communication was only chosen by $21.7 \%$ of the respondents. The results do not support $\mathrm{H} 2$, that tasks involving high equivocality and low uncertainty would lead to selection of a less rich medium like instant messaging or telephone. Instead, 53\% of the respondents preferred face-to-face interaction. Phone and IM fell to the bottom of the list at $2.4 \%$ and $1.2 \%$ respectively. The results do support H3, that tasks involving low equivocality and high uncertainty would lead to selection of a leaner medium such as Email. Email had the highest rank selection at 78.3\%. The results do not support H4, that tasks involving low equivocality and low uncertainty would lead to selection of a very lean medium such as letter or fax. Email was still the highest ranking choice for this category at $63.9 \%$ with letter and fax at the very bottom again. At this point, the results show extremely minimal support for media richness theory as an accurate predictor of media selection based on equivocality and uncertainty alone.

Table 6. Media choices based on task characteristics.

\begin{tabular}{|c|c|c|c|}
\hline High equivocality & & Low equivocality & \\
\hline High uncertainty & Low uncertainty & High uncertainty & Low uncertainty \\
\hline 1. Email (51.8\%) & 1. F2F (53\%) & 1. Email (78.3\%) & 1. Email (63.9\%) \\
\hline 2. F2F (21.7\%) & 2. Email (34.9\%) & 2. Letter/memo (10.8\%) & 2. F2F (19.3\%) \\
\hline 3. Letter/memo (13.3\%) & 3. Letter/memo (6\%) & 3. Phone (4.8\%) & 3. Phone (13.3\%) \\
\hline 4. Phone (10.8\%) & 4. Phone (2.4\%) & 4. $\operatorname{Fax}(3.6 \%)$ & 4. IM (2.4\%) \\
\hline 5. Fax $(1.2 \%)$ & 4. $\operatorname{Fax}(2.4 \%)$ & 5. F2F (1.2\%) & 5. Letter/memo (1.2\%) \\
\hline
\end{tabular}


High equivocality

High uncertainty

5. $\operatorname{IM}(1.2 \%)$
Low uncertainty

5. $\operatorname{IM}(1.2 \%)$
Low equivocality

High uncertainty

5. IM (1.2\%)

. $\operatorname{Fax}(0 \%)$

As seen in Table 7, a key finding is the heavy preponderance of Email selection as an appropriate medium choice regardless of task characteristics except for those tasks involving high equivocality and low uncertainty.

Table 7. Media task characteristics.

\begin{tabular}{l|l|l|l} 
& & & \\
& & & \\
\cline { 3 - 4 } & & Low & High \\
\hline Equivocalitainty & High & Face-to-face & Email \\
\cline { 2 - 4 } & Low & Email & Email \\
\hline
\end{tabular}

\subsection{Media choice: contextual analysis}

Media choice analysis was conducted for each of the contextual factors. Each of these is reported in subsequent subsections. As described earlier, a low and a high value of the contextual factor was added to each of the four base scenarios. The contextual results were compared with the base case results using Chi-Square tests to see if the observed frequency of media choice based on the context were significantly different from the expected frequency as in the base case. The $\mathrm{p}$ values of these tests are shown in Table 8 . Because the use of the Chi-Square test is inappropriate if any expected frequency is less than 5 , some groups had to be combined. In most contextual scenarios, the observed results were significantly different from the expected results. However there is a clear pattern in that there is no significant difference due to the contextual constraint in tasks with low equivocality, low uncertainty (LELU) and low value of the contextual constraint. This result is expected and important as when all of the characteristics and constraints are low, the media choice does not change significantly; whereas in other scenarios, the media choice does change highlighting the impact of context — the main thesis of this study. In other words, the situational context clearly and significantly affects the choice of the communication medium. 
Table 8. Chi Square tests comparing contextual scenarios with base cases.

\begin{tabular}{|c|c|c|c|c|}
\hline & HEHU & LELU & HELU & LEHU \\
\hline \multicolumn{5}{|c|}{ Urgency } \\
\hline High & 0.000 & 0.000 & 0.000 & 0.000 \\
\hline Low & 0.018 & 0.298 & 0.000 & 0.033 \\
\hline \multicolumn{5}{|c|}{ Social Interaction } \\
\hline High & 0.000 & 0.000 & 0.002 & 0.000 \\
\hline Low & 0.472 & 0.192 & 0.000 & 0.013 \\
\hline \multicolumn{5}{|c|}{ Confidentiality } \\
\hline High & 0.000 & 0.000 & 0.043 & 0.000 \\
\hline Low & 0.034 & 0.547 & 0.000 & 0.186 \\
\hline \multicolumn{5}{|c|}{ Information Integrity } \\
\hline High & 0.001 & 0.000 & 0.000 & 0.000 \\
\hline Low & 0.007 & 0.09 & 0.000 & 0.752 \\
\hline \multicolumn{5}{|c|}{ Accountability } \\
\hline High & 0.282 & 0.003 & 0.000 & 0.000 \\
\hline Low & 0.009 & 0.882 & 0.000 & 0.482 \\
\hline
\end{tabular}

\subsubsection{Need for urgency}

Table 9 shows the results of media choices within the context of high urgency and low urgency. The results show modest support for H5. High need for urgency significantly affected media selection, in most cases in the ways anticipated. The most preferred choices are Face to Face, Phone and Email. Face to Face and Phone were the hypothesized choices in H5. In low urgency situations, Email is the predominant choice of most respondents irrespective of equivocality and uncertainty. When the urgency level changes from high to low, the media selected by the respondent change in two scenarios: HELU and LELU; changes do not occur in the cases of HEHU and LEHU. The media choice changes from a verbal media to a written media in low 
urgency and low uncertainty situations. This is in agreement with the perception of feedback immediacy of different media in the literature as well as that presented in Table 4, where respondents perceive face-to-face and phone as higher in feedback immediacy over Email. Thus the hypothesis that a high need for task-related urgency will lead to the selection of a medium capable of delivering the communication urgently, such as face-to-face or phone, and be significantly different than the medium selection based on the match of task characteristics of equivocality and uncertainty alone is valid in half of the situations investigated in this study.

Table 9. Media choices within context of need for urgency.

\begin{tabular}{|c|c|c|c|c|}
\hline & High equivocality & & Low equivocality & \\
\hline & High uncertainty & Low uncertainty & High uncertainty & Low uncertainty \\
\hline \multirow[t]{6}{*}{ High urgency } & 1. Email (39.8\%) & 1. F2F (45.1\%) & 1. Email (64.6\%) & 1. Phone (47\%) \\
\hline & 2. Phone (27.7\%) & 2. Phone (30.5\%) & 2. Phone (17.1\%) & 2. F2F (28.9\%) \\
\hline & 3. F2F (26.5) & 3. Email (22\%) & 3. Fax $(6.1 \%)$ & 3. Email (19.3\%) \\
\hline & 4. Letter/memo (4.8\%) & 4. Letter/memo (1.2\%) & 4. Letter/memo (4.9\%) & 4. IM (4.8\%) \\
\hline & 5. IM (1.2\%) & 4. IM (1.2\%) & 4. IM (4.9\%) & 5. Fax $(0 \%)$ \\
\hline & 6. Fax $(0 \%)$ & 6. Fax (0\%) & 6. F2F (2.4\%) & 5. Letter/memo ( $0 \%)$ \\
\hline \multirow[t]{6}{*}{ Low urgency } & 1. Email (63.4\%) & 1. Email (54.9\%) & 1. Email (76.8\%) & 1. Email (66.3\%) \\
\hline & $\begin{array}{l}\text { 2. Letter/memo } \\
(18.3 \%)\end{array}$ & $\begin{array}{l}\text { 2. Letter/memo } \\
(20.7 \%)\end{array}$ & $\begin{array}{l}\text { 2. Letter/memo } \\
(18.3 \%)\end{array}$ & 2. F2F (22.9\%) \\
\hline & 3. F2F (11\%) & 3. F2F (17.1\%) & 3. F2F (2.4\%) & 3. Phone (6\%) \\
\hline & 4. Phone (6.1\%) & 4. Phone (4.9\%) & 4. Phone (1.2\%) & $\begin{array}{l}\text { 4. Letter/memo } \\
(3.6 \%)\end{array}$ \\
\hline & 5. Fax (1.2\%) & 5. Fax (2.4\%) & 4. Fax (1.2\%) & 5. Fax (1.2\%) \\
\hline & 6. IM (0\%) & 6. IM (0\%) & 6. IM (0\%) & 6. IM (0\%) \\
\hline
\end{tabular}

\subsubsection{Need for social interaction}

Table 10 shows the results of media choices within the context of high and low need for social interaction. The results show support for H6 in three of the four scenarios of high social interaction. Results show that while Email is the most preferred choice for the four base scenarios when there is low need for social interaction, this is not so when there is a need for 
high social interaction. The most preferred choice is face-to-face, as one would expect, for scenarios with a high need for social interaction, except in the scenario involving low equivocality and high uncertainty. Again, as per the literature and perceptions shown in Table 4, the media perceived as high in social presence are face-to-face and phone while Email is ranked low. Clearly individuals prefer face-to-face communication when they have a high need for social interaction and prefer Email when this need is low. Thus, the hypothesis that a high need for social interaction will lead to the selection of a medium with high social presence, such as face-to-face, and be significantly different than the medium selection based on the match of task characteristics of equivocality and uncertainty alone has support in all cases but LEHU.

Table 10. Media choices within context of need for social interaction.

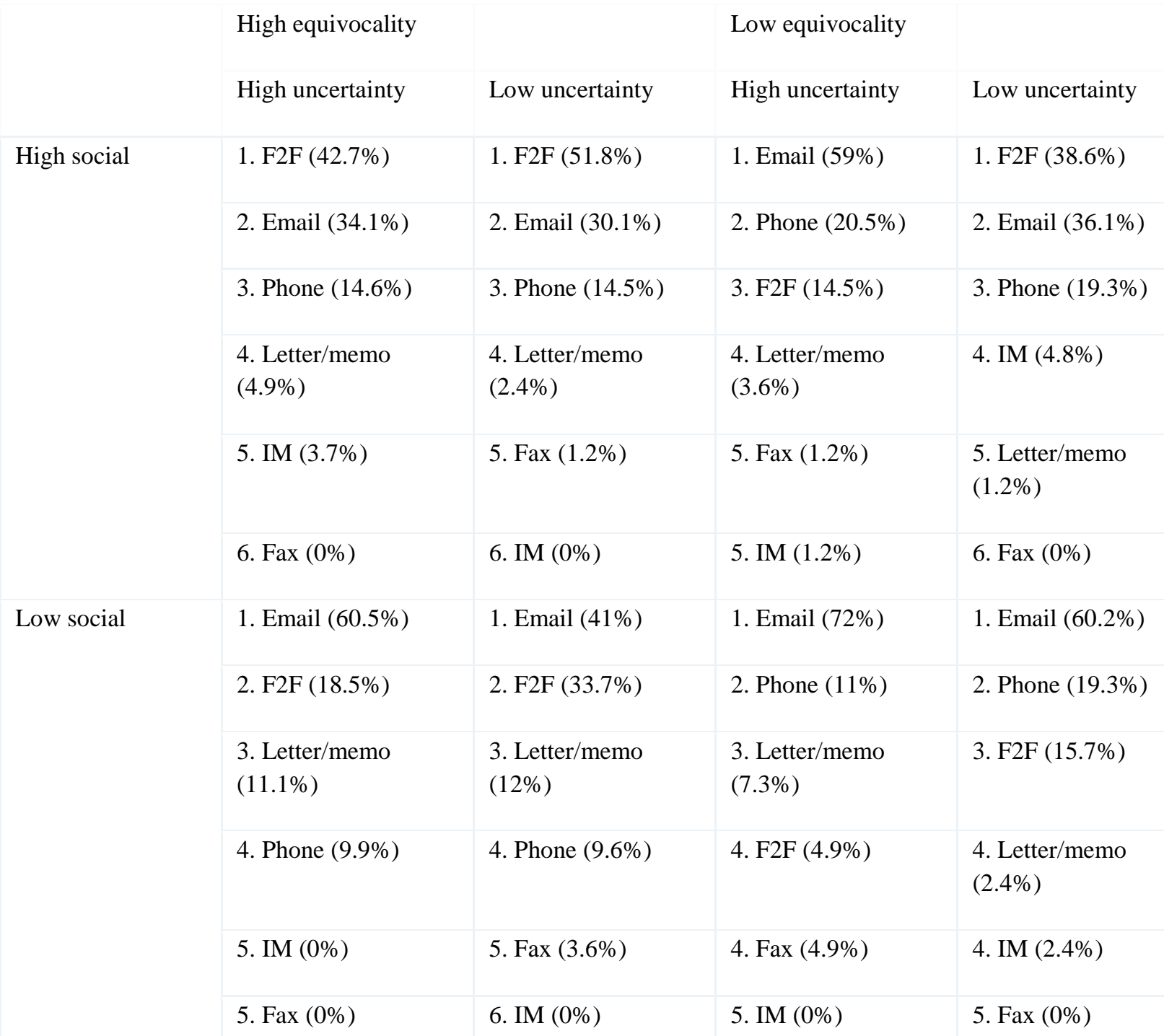

\subsubsection{Need for confidentiality}


Table 11 shows the results of media choices within the context of high and low need for confidentiality. The results show support for $\mathrm{H7}$ in three of four scenarios of high confidentiality. Email is still the first choice of a majority of the respondents when there is little need for confidentiality. However, when the requirements of confidentiality are high, the most preferred choice is face-to-face for all scenarios, except in the case of low equivocality and high uncertainty. The need for higher confidentiality also led to a change in the selected media except in situations involving low equivocality and high uncertainty, where there is no change. Again as shown in Table 4, the media perceived as high ranking on the security needs of individuals are face-to-face and phone, and low ranking is Email. Thus, the hypothesis that a high need for taskrelated confidentiality will lead to the selection of a medium perceived to be secure from the sender's perspective, such as face-to-face, and be significantly different than the medium selection based on the match of task characteristics of equivocality and uncertainty alone has support in all cases but LEHU.

Table 11. Media choices within context of need for confidentiality.

\begin{tabular}{|c|c|c|c|c|}
\hline & High equivocality & & Low equivocality & \\
\hline & High uncertainty & Low uncertainty & High uncertainty & Low uncertainty \\
\hline \multirow[t]{6}{*}{ High confidentiality } & 1. F2F (37.3\%) & 1. F2F (57.8\%) & 1. Email (38.6\%) & 1. F2F (42.2\%) \\
\hline & 2. Email (26.5\%) & 2. Email (24.1\%) & 2. F2F (21.7\%) & 2. Phone (27.7\%) \\
\hline & 3. Phone (22.9\%) & 3. Phone (12\%) & $\begin{array}{l}\text { 3. Letter/memo } \\
(20.5 \%)\end{array}$ & 3. Email (21.7\%) \\
\hline & $\begin{array}{l}\text { 4. Letter/memo } \\
(10.8 \%)\end{array}$ & $\begin{array}{l}\text { 4. Letter/memo } \\
(6 \%)\end{array}$ & 4. Phone (13.3\%) & $\begin{array}{l}\text { 4. Letter/memo } \\
(7.2 \%)\end{array}$ \\
\hline & 5. Fax (2.4\%) & 5. Fax $(0 \%)$ & 5. Fax $(4.8 \%)$ & 5. Fax $(1.2 \%)$ \\
\hline & 6. IM (0\%) & 5. IM (0\%) & 6. IM (1.2\%) & 6. IM (0\%) \\
\hline \multirow[t]{6}{*}{ Low confidentiality } & 1. Email (64.6\%) & 1. Email (44.6\%) & 1. Email (74.7\%) & 1. Email (63.9\%) \\
\hline & 2. F2F (13.4\%) & 2. F2F (32.5\%) & $\begin{array}{l}\text { 2. Letter/memo } \\
(8.4 \%)\end{array}$ & 2. F2F (15.7\%) \\
\hline & 3. Phone (12.2\%) & 3. Phone (10.8\%) & 3. $\operatorname{Fax}(7.2 \%)$ & 3. Phone (9.6\%) \\
\hline & $\begin{array}{l}\text { 4. Letter/memo } \\
(6.1 \%)\end{array}$ & $\begin{array}{l}\text { 4. Letter/memo } \\
(6 \%)\end{array}$ & 4. F2F (6\%) & $\begin{array}{l}\text { 4. Letter/memo } \\
(4.8 \%)\end{array}$ \\
\hline & 5. Fax (3.7\%) & 4. $\operatorname{Fax}(6 \%)$ & 5. Phone (2.4\%) & 4. IM (4.8\%) \\
\hline & 6. IM (0\%) & 5. IM (0\%) & 6. IM (1.2\%) & 5. Fax $(1.2 \%)$ \\
\hline
\end{tabular}




\subsubsection{Need for information integrity}

Table 12 shows the results of media choices within the context of high and low need for information integrity. The results do not support $\mathrm{H8}$ as in the four high integrity cases, Email is the preferred choice in three and face-to-face is the choice in one. To be fair, as hypothesized, letter/memo is the second choice in two of the high integrity cases. The results show that the selection of Email as the most preferred choice does not change for scenarios with a high and low need for information integrity, except for the scenario involving high equivocality and low uncertainty, where face-to-face is preferred at $33.7 \%$. The need for higher information integrity causes change in the selected media only in the one situation of high equivocality and low uncertainty. Once again, when the need for information integrity is low, Email is the preferred medium in all of the four base scenarios. Thus the hypothesis that a high need for task-related information integrity will lead to the selection of a medium perceived to be capable of maintaining high levels of information integrity, such as face-to-face, and be significantly different than the medium selection based on the match of task characteristics of equivocality and uncertainty alone is not supported in any of the four high information integrity cases.

Table 12. Media choices within context of need for information integrity.

\begin{tabular}{|c|c|c|c|c|}
\hline & High equivocality & & Low equivocality & \\
\hline & High uncertainty & Low uncertainty & High uncertainty & Low uncertainty \\
\hline \multirow[t]{6}{*}{ High integrity } & 1. Email (33.7\%) & 1. F2F (33.7\%) & 1. Email (55.4\%) & 1. Email (42.2\%) \\
\hline & $\begin{array}{l}\text { 2. Letter/memo } \\
(22.9 \%)\end{array}$ & 2. Email (27.7\%) & $\begin{array}{l}\text { 2. Letter/memo } \\
(22.9 \%)\end{array}$ & 2. Phone (21.7\%) \\
\hline & 3. F2F (20.5\%) & $\begin{array}{l}\text { 3. Letter/memo } \\
(22.9 \%)\end{array}$ & 3. F2F (9.6\%) & 3. F2F (20.5\%) \\
\hline & 4. Phone (19.3\%) & 4. Phone (12\%) & 4. Fax (6\%) & $\begin{array}{l}\text { 4. Letter/memo } \\
(12 \%)\end{array}$ \\
\hline & 5. Fax (3.6\%) & 5. Fax (3.6\%) & 4. Phone (6\%) & 5. Fax (2.4\%) \\
\hline & 6. IM (0\%) & 6. IM (0\%) & 5. IM (0\%) & 6. IM (1.2\%) \\
\hline \multirow[t]{3}{*}{ Low integrity } & 1. Email (68.7\%) & 1. Email (59\%) & 1. Email (77.1\%) & 1. Email (63.9\%) \\
\hline & 2. Phone (13.3\%) & 2. F2F (15.7\%) & $\begin{array}{l}\text { 2. Letter/memo } \\
(9.6 \%)\end{array}$ & 2. Phone (18.1\%) \\
\hline & $\begin{array}{l}\text { 3. Letter/memo } \\
(9.6 \%)\end{array}$ & 3. Phone (13.3\%) & 3. Phone (7.2\%) & 3. F2F (12\%) \\
\hline
\end{tabular}




\begin{tabular}{llll} 
High equivocality & \multicolumn{3}{c}{ Low equivocality } \\
High uncertainty & Low uncertainty & High uncertainty & Low uncertainty \\
\hline 4. F2F $(8.4 \%)$ & $\begin{array}{l}\text { 4. Letter/memo } \\
(10.8 \%)\end{array}$ & 4. Fax (3.6\%) & $\begin{array}{l}\text { 4. Letter/memo } \\
(2.4 \%)\end{array}$ \\
\hline 5. Fax (0\%) & 5. Fax (1.2\%) & 5. F2F (2.4\%) & 4. Fax (2.4\%) \\
\hline 5. IM (0\%) & 6. IM $(0 \%)$ & 6. IM $(0 \%)$ & 5. IM $(1.2 \%)$
\end{tabular}

\subsubsection{Need for accountability}

Table 13 shows the results of media choice within the context of high and low need for accountability. The results support $\mathrm{H} 9$ in all cases as Email was selected as the most preferred medium in all four scenarios of high accountability. Face-to-face was fairly consistently the second highest rank except in the scenarios involving low equivocality and high uncertainty. However, as in all of the previous contexts where Email was the preferred choice for the low value of the context, Email was also the preferred choice when the need for accountability was low. But in all other contexts, when the context changed from low to high value, the preferred media choice almost always changed; but in the present case, it remained as Email. Thus we have a very significant finding which indicates that the need for accountability does affect media choice in all of the four base scenarios. Our findings support the arguments made by Salmon and Joiner [35] based on feature theory that the feature of email to provide an audit trail in current climate of increased corporate governance is one of the primary reason of its selection over other communication media. Thus, the hypothesis that a high need for individual and task-related accountability will lead to the selection of a medium perceived to provide more accountability from the sender's perspective, such as Email, and be significantly different than the medium selection based on the match of task characteristics of equivocality and uncertainty alone found total support.

Table 13. Media choices within context of need for accountability.

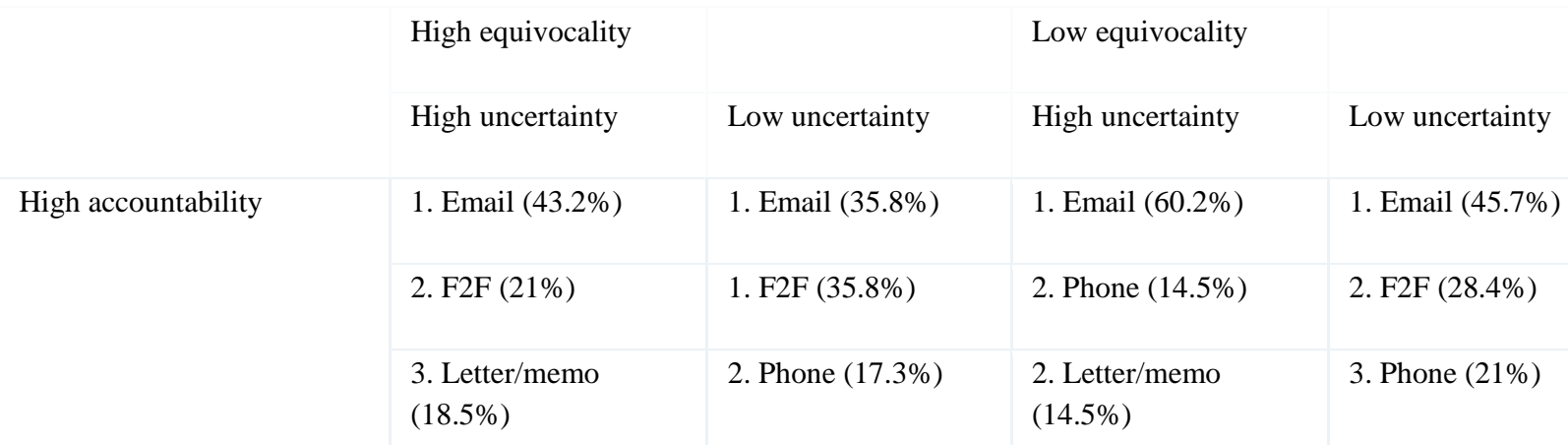




\begin{tabular}{|c|c|c|c|c|}
\hline & High equivocality & & Low equivocality & \\
\hline & High uncertainty & Low uncertainty & High uncertainty & Low uncertainty \\
\hline & 4. Phone (16\%) & $\begin{array}{l}\text { 3. Letter/memo } \\
(8.6 \%)\end{array}$ & 3. Fax (6\%) & $\begin{array}{l}\text { 4. Letter/memo } \\
(3.7 \%)\end{array}$ \\
\hline & 5. IM (1.2\%) & 4. $\operatorname{Fax}(1.2 \%)$ & 4. F2F (4.8\%) & 5. IM (1.2\%) \\
\hline & 6. Fax $(0 \%)$ & 4. IM (1.2\%) & 5. IM (0\%) & 6. Fax $(0 \%)$ \\
\hline Low accountability & 1. Email (69.9\%) & 1. Email (60.5\%) & 1. Email (79\%) & 1. Email (65.4\%) \\
\hline & 2. F2F (10.8\%) & 2. F2F (17.3\%) & $\begin{array}{l}\text { 2. Letter/memo } \\
(7.4 \%)\end{array}$ & 2. F2F (17.3\%) \\
\hline & $\begin{array}{l}\text { 2. Letter/memo } \\
(10.8 \%)\end{array}$ & 3. Phone (13.6\%) & 3. Phone (6.2\%) & 3. Phone (12.3\%) \\
\hline & 3. Phone (3.6\%) & $\begin{array}{l}\text { 4. Letter/memo } \\
(8.6 \%)\end{array}$ & 4. Fax (3.7\%) & 4. IM (3.7\%) \\
\hline & 3. Fax (3.6\%) & 5. Fax (0\%) & 4. F2F (3.7\%) & $\begin{array}{l}\text { 5. Letter/memo } \\
(1.2 \%)\end{array}$ \\
\hline & 4. IM (1.2\%) & 5. IM (0\%) & 5. IM (0\%) & 6. Fax $(0 \%)$ \\
\hline
\end{tabular}

Overall, the results show little support for the media richness theory as an accurate predictor of media choice. In scenarios without contextual constraints, equivocality and uncertainty do not guide media selection in the expected ways. Furthermore, in a majority of the cases, contextual constraints dominate over equivocality and uncertainty in the selection of appropriate media. While equivocality and uncertainty may still be important considerations in media selection, contextual constraints seem to have an overriding role in media selection.

\section{Discussion}

Previously, Table 8 captured the significant and non-significant differences between media selection outcomes with and without contextual constraints. Table 14 provides a quick summary of the results. 
Table 14. Summary of results.

\begin{tabular}{|c|c|c|c|}
\hline & Hypothesis & Description & Support \\
\hline \multirow[t]{4}{*}{$\begin{array}{l}\text { Task } \\
\text { characteristics }\end{array}$} & H1 & $\begin{array}{l}\text { High equivocality and high uncertainty } \\
\text { lead to face-to-face. }\end{array}$ & No \\
\hline & $\mathrm{H} 2$ & $\begin{array}{l}\text { High equivocality and low uncertainty } \\
\text { lead to IM and phone. }\end{array}$ & No \\
\hline & H3 & $\begin{array}{l}\text { Low equivocality and high uncertainty } \\
\text { lead to Email. }\end{array}$ & Yes \\
\hline & $\mathrm{H} 4$ & $\begin{array}{l}\text { Low equivocality and low uncertainty } \\
\text { lead to letter or fax. }\end{array}$ & No \\
\hline \multirow[t]{5}{*}{$\begin{array}{l}\text { Contextual } \\
\text { constraints }\end{array}$} & H5 & $\begin{array}{l}\text { High need for urgency leads to face-to- } \\
\text { face or phone. }\end{array}$ & Supported in 2 of 4 cases \\
\hline & H6 & $\begin{array}{l}\text { High need for social interaction leads } \\
\text { to face-to-face. }\end{array}$ & Supported in 3 of 4 cases \\
\hline & H7 & $\begin{array}{l}\text { High need for confidentiality leads to } \\
\text { face-to-face. }\end{array}$ & Supported in 3 of 4 cases \\
\hline & H8 & $\begin{array}{l}\text { High need for information integrity } \\
\text { leads to letter or memo. }\end{array}$ & $\begin{array}{l}\text { Not supported. Second } \\
\text { choice in } 2 \text { of } 4 \text { cases }\end{array}$ \\
\hline & H9 & $\begin{array}{l}\text { High need for accountability leads to } \\
\text { Email. }\end{array}$ & Supported in all cases \\
\hline
\end{tabular}

The pattern of no significant differences in group proportions where uncertainty, equivocality, and contextual constraint are all low was expected, since media choice should not change significantly when none of the factors are overriding. What is more important to note is that when any of the five situational contexts was held at a high value, the media choices were significantly different in most cases, in fact in 19 out of the 20 situations. This is an important finding because it clearly demonstrates that contextual constraints have a significant impact on media selection in almost every single scenario. It is important to note that while all of the changes in media selection were significant under high contextual constraints, as predicted in H5, H6, H7, H8 and H9, the changes had little relationship with media richness theory. For example, when media richness theory might have pointed to a preference for a very rich medium like face-to-face, the most frequent preference was Email. 
The dominance of Email for communication is clear in all of the scenarios. In fact, Email is the preferred choice in every single case where the contextual constraint is held at a low value; a total of 20 cases. Even when any of the contextual constraint is held at a higher value, Email is the preferred choice in 11 of the 20 cases. All total, Email is the preferred choice in 31 or in 78\% of the cases. Thus the study points to the fact that people choose Email over other forms of communication most of the time. One explanation for Email being one of the most preferred media could be that it is being used on a large and still increasing scale and has reached a stage of maturity almost comparable to that of traditional media, like the telephone [16]. Existing literature supports our results and points to the notion that Email has become "ubiquitous in organizations" and it is impossible to imagine organizational communication without Email [32].

One reason why Email may be so popular is shown in Table 4, where Comfort Level for Email measured even higher than Telephone. On the one hand, this seems counterintuitive since most people have been using a phone longer than they have been using Email. On the other hand, Email may be more comfortable for people who are afraid of the phone and do not want to interact with people directly or want to avoid conflict. It is to be noted that while Email is generally considered one of the most successful and important computer applications, it has several undesirable effects such as information overload, spam, and partially read documents [48].

Another possible explanation for the preponderance of Email as the preferred choice of medium is that Email is simply a richer medium than originally thought or, more precisely, it is a richer media than it was ten years ago. If richness is defined by immediacy of feedback and variety of cues, then perhaps Email needs to be reevaluated for richness. People frequently receive Email responses within minutes if not seconds (although this is by no means guaranteed), so the potential for immediacy of feedback is present. And perhaps more visual cues are communicated in Email beyond the text itself, especially with HTML mail where different parts of a message can have different font properties and even have pictures embedded in the messages. In fact, Lee [21] has vividly described how richness can occur in Email communication and can rival the richness in so-called "richer" media such as face to face. Similar views are expressed by Hooff et al. [16], who state that media perceptions and their relative richness change with users' experience and expertise with particular media.

Also, the continuous use of Email as preferred means of communication, can find some explanation from the most recent research on habit formation [14] and [24]. As Guenea and Markus [14] state that over time, in stable contexts, continuing IT use becomes habitual, which 
means that well-learned action sequences may be activated by environmental cues and then repeated without conscious intention.

In one instance, the use of Email appears to be appropriate and justified. When need for high accountability was of paramount importance, Email was preferred in every single scenario. The most likely explanation for this phenomenon is that people consider Email to be a good way to hold people accountable in terms of having an audit trail of conversations where it would be difficult to have a similar audit trail in a face to face conversation that could be denied later. The common business term for this phenomenon is called "CYA" and the data seems to support this practice, regardless of whether this is a proper use of the media or not. Email possesses the characteristics of plasticity, which is the ability to save, store and retrieve messages [29], and makes it the preferred medium for situations requiring official and legally binding documentation, and guaranteed authorship.

A pattern seemed to emerge when uncertainty was high and equivocality was low, i.e., LEHU. The media choice in each of these LEHU scenarios was an exception to the prediction, particularly when there was high need for social interaction and high need for confidentiality. In all LEHU cases, Email was selected. There are several explanations. First, as discussed earlier, Email is not necessarily a lean medium and is fully capable of carrying large amounts of information in relatively fast transmission. Another explanation may be that people simply do not want to have 40 different face-to-face conversations with 40 different regional managers in the LEHU scenarios. Even though face-to-face interaction might have increased the level of social interaction and confidentiality, the practicality of sending one Email simultaneously to a large number of people trumped having 40 different conversations.

The answer to the primary research question: do contextual constraints significantly affect media choice over and above the traditional task characteristics of equivocality and uncertainty, is a resounding yes. In each case of high contextual constraint, the difference in the proportion of media selection was significantly different in 19 out of the 20 scenarios. The answer to the second research question: does media richness theory have effective predictive power over media selection in organizations, appears to be negative based on this investigation and may demand further investigation. We know that task characteristics by themselves are not enough to predict media selection based on the results of $\mathrm{H} 1, \mathrm{H} 2, \mathrm{H} 3$ and $\mathrm{H} 4$. While the addition of contextual constraints did significantly impact media choice, it deviated in most cases away from media choice theory and showed preponderance of Email as the preferred selection. This result again pulls away from the applicability of the media richness theory in most cases. Hooff, Groot, and Jonge [16] also conclude in their meta-analysis that situational factors and ability of Email to 
overcome time and space clearly influence its perceived applicability, and this applicability is more dependent on situational constraints on communication task than on any fit between task and medium. Thus we ask whether MRT is really a good predictor of media choice. The answer at this point is no. The explanatory model of MRT is too simplistic to have substantial predictive power, or provide normative guidance for media choice. Our findings are also in line with D'Ambra, Rice, and O' Connor [8] who question the objective character of media richness and show that task equivocality and media richness are not unidimensional; instead, they interact with other variables that may affect media choice.

Based on our investigation, media and information richness may have to be supplemented with newer perspectives. For one thing, a medium may be capable of multiple forms of richness, such as Email and many emerging web-based technologies. Another possibility is to break a task into sub-parts, as suggested by the recent Media Synchronicity Theory [10], which divides a communication task into two processes: conveyance and convergence. This theory postulates that communication performance is enhanced when media capabilities are properly aligned with the requirements of these two processes. Still this theory fails to account for the contextual constraints and media with multiple capabilities. As we have witnessed in this research, context is important and simply cannot be ignored in media choice research. As in many disciplines (e.g., psychology, education, and politics), our finding suggests that context is everything in media selection. Unfortunately, media richness theory ignores context.

\section{Limitations and future research}

One of the limitations of this study is the use of Master's students for the sample. However, based on the sample's demographics and average work experience, they can be considered fairly representative of the workforce as a whole. Furthermore, while our study was targeted at organizational actors in general, it did not distinguish between managers and employees. Such a distinction may have the possibility of providing further insights. A second limitation may be the types of scenarios used for the study. We selected four scenarios to represent different levels of uncertainty and equivocality. While these were somewhat contrived, they were based on prior literature and were pilot tested. Future research may wish to conduct such studies with organizational members involved in real communications tasks. There were only five contextual factors examined in this study, but there are surely others that could be examined in the future (for example, power, trust, control, politics, security, privacy and individual characteristics). However, it is noteworthy that many of the unexplored factors manifest themselves into the ones that we did investigate. For example, lack of trust or need for control may result in higher urgency and accountability, and higher security and privacy may require greater confidentiality. Another possibility for future research is to investigate the impact of the national culture 
dimensions of the actors involved in the communication process, e.g., power distance, uncertainty avoidance, masculinity-femininity, individualism-collectivism, and long-term orientation [15].

We studied the impact of each contextual factor in isolation. What if two or more contextual factors are in existence simultaneously? What are their combined effects and how do they interact? While the media choices were limited to the six most widely used in the literature, new media are evolving every day and new possibilities such as Avatar Email may become popular enough for inclusion. Critical mass theory and cognitive behaviors may account for the reasons that Email and face-to-face communication were chosen most frequently, and this is a suggested area for future study. We believe that many small steps may have to be undertaken before proposing a comprehensive theory for media choice.

\section{Implications and conclusions}

This research extends our understanding of media choice by adding the important element of context to the traditional factors of media choice selection, namely task equivocality and task uncertainty. Five contextual constraints were hypothesized to affect media selection made by managers to communicate information. The interaction between traditional task characteristics and contextual constraints is helpful in understanding media choice when an individual is faced with competing needs for selecting particular media, beyond those required by task. Hence, from a theoretical perspective, our research contributes to extending the media richness theory, and departs from prior work by focusing on factors affecting media choice that have not been investigated before. Our findings lay the groundwork for situational and context-aware theories for media selection. Future research in understanding media preference and choice should consider these results and the importance of situational constraints over and beyond task constraints.

From the standpoint of practitioners, evidence from our study would help managers and organizations in redesigning their communication media portfolios. Organizations and managers seeking to align communication strategies will benefit from our findings by promoting and providing media to their employees which are more suited to the context of communication instead of characteristics like richness of the media. Huge investments in media which do not match with the culture and structure of the organization can be minimized if it is known which factors are important and what media are selected based on these factors. This study is also helpful to media designers in incorporating contextual features in the media without restricting the traditional rationale of task based media design. Results will also benefit the recipients of 
organizational communication in better appreciating and understanding the intrinsic motivation of the sender and the context of the communication based on media selection.

The paradox of media choice research is that even though face-to-face is a better medium for immediacy of feedback and variety of cues, Email has emerged as the most prevalent choice. This will be vital for organizations to understand. "At home on their own e-mail account, employees can be flippant as they want with their e-mail, but when they write something at work, their e-mail is being written on corporate stationary, and they should not write anything they wouldn't say in an open business meeting” [46]. The lines between personal and business Email can be blurred by both managers and employees, especially when conversing with people who are more than just work colleagues. A clear Email policy needs to be communicated to all employees to "protect staff from embarrassment-and maybe even some legal consequences" [46]. Especially in cases where employees need to communicate private information such as trade secrets, financial information, or client/patient information, policies need to be in force to help managers and employees make appropriate media choices.

Communication is one of the key functions of any manager in any business, but how the media choice should be made is still unclear. We know that task characteristics coupled with contextual constraints are part of the answer but we still do not have the complete picture. We do know that we need to go beyond information and media richness.

Appendix A

Question

1. Please indicate the media choices currently available at your disposal according to the $1-5$ scale below:

2. Please indicate your level of comfort using the following media:

3. Please indicate your perceptions toward security with regard to following types of media by marking the appropriate number in each box.

4. Please indicate your perception of how immediate the feedback is for each of the following types of communications:

5. Please indicate your perception of how many cues (both verbal and nonverbal including graphic symbols, gestures, sounds, voice inflection, gestures and other aids to enhance the communication message) you get through each of the following types of communications:
Measuring

Perceived availability of media

Perceived comfort level with media

Perceived security of media

Perceived feedback immediacy of media

Perceived cues of media 
6. Please indicate your perception of how sociable each of the following types of communication are:

Perceived sociability of media

7. Please rank the following media from 1 to 6 based on their capability to carry Perceived capability desired amount of information from low amount of information to high amount of information.

Given your current environment, please select the type of communication you would use in each of the following communication scenarios. Consider each as a separate scenario-they are not based upon each other.

1. There has been disagreement about how to proceed with the implementation of HELU a new information security policy and you need to resolve the issue with your project group of 10 members.

2. You need to contact colleagues from the 20 departments in your company to HEHU discuss the variance in the sales of several of your major product lines. The sales have fluctuated rapidly and seemingly without a pattern.

3. You want to gather the birth date (month and day) of the five colleagues in your LELU department.

4. You want to gather an extensive set of standard sales figures from the 40 LEHU regional managers in your organization.

5. You need to contact colleagues from the 20 departments in your company to discuss the variance in the sales of several of your major product lines. The sales have fluctuated rapidly and seemingly without a pattern. This needs to be completed as soon as possible.

6. You want to gather the birth date (month and day) of the five colleagues in your department. There is no urgency for this information.

LELU - low urgency

7. There has been disagreement about how to proceed with the implementation of a new information security policy and need resolve the issue with your project group of 10 members. This needs to be completed as soon as possible.

HELU — high urgency

8. You need to contact colleagues from the 20 departments in your company to HEHU — high social discuss the variance in the sales of several of your major product lines. The sales have fluctuated rapidly and seemingly without a pattern. You have worked closely with this group in the past and enjoy their company.

9. You want to gather an extensive set of standard sales figures from the 40 LEHU — high regional managers in your organization. This needs to be completed as soon as possible.

urgency 
10. There has been disagreement about how to proceed with the implementation of

HELU - low a new information security policy and you need to resolve the issue with your project group of 10 members. There is no urgency in completing this resolution.

11. You need to contact colleagues from the 20 departments in your company to HEHU — low discuss the variance in the sales of several of your major product lines. The sales have fluctuated rapidly and seemingly without a pattern. There is no urgency for the collection of this information.

12. You want to gather an extensive set of standard sales figures from the 40

LEHU — low regional managers in your organization. There is no urgency for this information.

13. You want to gather the birth date (month and day) of the five colleagues in your department. This needs to be completed as soon as possible for the company directory deadline.

14. You need to contact colleagues from the 20 departments in your company to discuss the variance in the sales of several of your major product lines. The sales have fluctuated rapidly and seemingly without a pattern. This information must be kept confidential.

15. You want to gather the birth date (month and day) of the five colleagues in your department. The birth dates are to be kept confidential.

16. There has been disagreement about how to proceed with the implementation of a new information security policy and you need to resolve the issue with your project group of 10 members. This information must be kept confidential.

17. You want to gather an extensive set of standard sales figures from the 40 regional managers in your organization. This information is to be kept confidential.

18. There has been disagreement about how to proceed with the implementation of a new information security policy and you need to resolve the issue with your project group of 10 members. This information has been discussed openly and is not confidential.

19. You want to gather the birth date (month and day) of the five colleagues in your department. This information will go into the company directory and is not confidential.

20. You need to contact colleagues from the 20 departments in your company to discuss the variance in the sales of several of your major product lines. The sales have fluctuated rapidly and seemingly without a pattern. This information has been discussed openly and is not confidential.
LELU — high urgency

HEHU — high confidentiality

LELU - high confidentiality

HELU — high confidentiality

LEHU — high confidentiality

HELU - low confidentiality

LELU - low confidentiality

HEHU — low confidentiality urgency

urgency 
21. You want to gather an extensive set of standard sales figures from the 40 regional managers in your organization. You are responsible and accountable for collection of this information.

22. You want to gather an extensive set of standard sales figures from the 40 regional managers in your organization. This information has been discussed openly and is not confidential.

23. You need to contact colleagues from the 20 departments in your company to discuss the variance in the sales of several of your major product lines. The sales have fluctuated rapidly and seemingly without a pattern. You are not held accountable or responsible for this information.

24. There has been disagreement about how to proceed with the implementation of a new information security policy and you need to resolve the issue with your project group of 10 members. You have worked closely with this group in the past and enjoy their company.

25. You want to gather the birth date (month and day) of the five colleagues in your department. You have worked closely with this group in the past and enjoy their company.

26. There has been disagreement about how to proceed with the implementation of a new information security policy and you need to resolve the issue with your project group of 10 members. You are interested in communicating with these members only about information pertaining to the project.

27. You want to gather an extensive set of standard sales figures from the 40 regional managers in your organization. You have worked closely with this group in the past and enjoy their company.

28. You want to gather the birth date (month and day) of the five colleagues in your department. You are interested in communicating with them to gather only the necessary information.

29. You want to gather an extensive set of standard sales figures from the 40 regional managers in your organization. You are interested in communicating with them to gather only the necessary information.

30. There has been disagreement about how to proceed with the implementation of a new information security policy and you need to resolve the issue with your project group of 10 members. The information you communicate must have integrity and accuracy.

31. You need to contact colleagues from the 20 departments in your company to discuss the variance in the sales of several of your major product lines. The sales
LEHU - high accountability

LEHU - low confidentiality

HEHU - low accountability

HELU — high social

LELU — high social

HELU — low social

LEHU — high social

LELU — low social

LEHU — low social

HELU — high integrity

HEHU — high integrity 
have fluctuated rapidly and seemingly without a pattern. The information you communicate must have integrity and accuracy.

32. You want to gather an extensive set of standard sales figures from the 40 regional managers in your organization. The information you communicate must have integrity and accuracy.

33. You want to gather the birth date (month and day) of the five colleagues in your department. The information you communicate must have integrity and accuracy.

34. There has been disagreement about how to proceed with the implementation of a new information security policy and you need to resolve the issue with your project group of 10 members. There is no special requirement for accuracy or integrity in this communication.

35. You need to contact colleagues from the 20 departments in your company to discuss the variance in the sales of several of your major product lines. The sales have fluctuated rapidly and seemingly without a pattern. There is no special requirement for accuracy or integrity in this communication.

36. You want to gather the birth date (month and day) of the five colleagues in your department. There is no special requirement for accuracy or integrity in this communication.

37. You want to gather an extensive set of standard sales figures from the 40 regional managers in your organization. There is no special requirement for accuracy or integrity in this communication.

38. There has been disagreement about how to proceed with the implementation of a new information security policy and you need to resolve the issue with your project group of 10 members. You are responsible and accountable for gathering this information.

39. You need to contact colleagues from the 20 departments in your company to discuss the variance in the sales of several of your major product lines. The sales have fluctuated rapidly and seemingly without a pattern. You are responsible and accountable for collection of this information.

40. You want to gather the birth date (month and day) of the five colleagues in your department. You are responsible and accountable for collection of this information.

41. There has been disagreement about how to proceed with the implementation of a new information security policy and you need to resolve the issue with your project group of 10 members. You are not held accountable or responsible for this
LEHU — high integrity

LELU — high integrity

HELU - low integrity

HEHU — low integrity

LELU — low integrity

LEHU — low integrity

HELU - high accountability

HEHU — high accountability

LELU — high accountability

HELU - low accountability 
information.

42. You need to contact colleagues from the 20 departments in your company to

HEHU - low social discuss the variance in the sales of several of your major product lines. The sales have fluctuated rapidly and seemingly without a pattern. You are interested in communicating with these members only about information pertaining to the sales fluctuations.

43. You want to gather the birth date (month and day) of the five colleagues in

LELU - low

your department. You are not held accountable or responsible for this information.

accountability

44. You want to gather an extensive set of standard sales figures from the 40

LEHU - low regional managers in your organization. You are not held accountable or responsible for this information.

accountability

\section{References}

P.J. Carlson, G.B. Davis. An investigation of media selection among directors and managers: from “self” to “other” orientation. MIS Quarterly, 22 (1998), pp. 335-362

J.R. Carlson, R.W. Zmud. Channel expansion theory and the experiential nature of media richness perceptions. Academy of Management Journal, 42 (1999), pp. 153-170

J.M. Carroll. Computer Security (3rd edition)Butterworth-Heinemann (1996)

K.C. Cousins, D. Robey. Human agency in a wireless world: patterns of technology use in nomadic computing environments. Information and Organization, 15 (2) (April 2005), pp. 151180

K. Chen, D. Yen, S. Hung, A. Huang. An exploratory study of the selection of communication media: the relationship between flow and communication outcomes. Decision Support Systems, 45 (2008), pp. 822-832

R.L. Daft, R.H. Lengel. Organizational information requirements, media richness and structural design. Management Science, 32 (1986), pp. 554-571

R.L. Daft, R.H. Lengel, L.K. Trevino. Message equivocality, media selection, and manager performance: implications for information systems. MIS Quarterly, 11 (1987), pp. 355-366

J. D'Ambra, R.E. Rice, M. O'Connor. Computer mediated communication and media preference. an investigation of the dimensionality of perceived task equivocality and media richness.

Behavior and Information Technology, 17 (3) (1998), pp. 164-174 
A. Dennis, S. Kinney. Testing media richness theory in the new media: the effects of cues, feedback, and task equivocality. Information Systems Research, 9 (3) (1998), pp. 256-274

A. Dennis, R. Fuller, J. Valacich. Media, tasks, and communication processes: a theory of media synchronicity. MIS Quarterly, 32 (3) (2008), pp. 575-600

F. Farhamand, S. Navathe, G. Sharpt, P. Enslow. Managing vulnerabilities of information systems to security incidents. Communications of the ACM - Proceedings of the 5th International Conference on Electronic Commerce (September 2003)

J. Fulk, B. Boyd. Emerging theories of communication in organizations. Journal of Management, 17 (1991), pp. 407-446

J. Fulk. Social construction of communication technology. Academy of Management Journal, 36 (1993), pp. 921-950

A. Guinea, M. Markus. Why break the habit of a lifetime? Rethinking the roles of intention, habit, and emotion in continuing information technology use. MIS Quarterly, 33 (3) (2009), pp. 433-444

G. Hofstede. Cultures and Organizations: Software of the Mind. McGraw-Hill, London (1991)

B. Hooff, J. Groot, S. Jonge. Situational influences on the use of communication technologies: a meta analysis and exploratory study. Journal of Business Communication, 41 (2) (2005), pp. 427

N. Johnson, R. Cooper. Media, affect, concession, and agreement in negotiation: IM versus telephone. Decision Support Systems, 46 (2009), pp. 673-684

S. Kahai, R. Cooper. Exploring the core concepts of media richness theory: the impact of cue multiplicity and feedback immediacy on decision quality

Journal of Management Information Systems, 21 (1) (2003), pp. 263-299

R. King, W. Xia. Media appropriateness: effects of experience on communication media choice. Decision Sciences, 28 (4) (1997), pp. 877-910

W. King, J. He. A meta-analysis of the technology acceptance model. Information \& Management, 43 (6) (2006), pp. 740-755

M. Kishi. Perceptions and use of electronic media: testing the relationship between organizational interpretation differences and media richness. Information \& Management, 45 (2008), pp. 281-287

A.S. Lee. Electronic mail as a medium for rich communication: an empirical investigation using hermeneutic interpretation. MIS Quarterly, 18 (1994), pp. 143-157 
Y. Lee, K. Kozar, K. Larsen. Avatar e-mail versus traditional e-mail: perceptual difference and media selection difference. Decision Support Systems, 46 (2009), pp. 451-467

M. Limayem, S. Hirt, C. Cheung. How habit limits the predictive power of intention: the case of information system continuance. MIS Quarterly, 31 (4) (2007), pp. 705-737

M.L. Markus. Electronic mail as the medium of managerial choice. Organization Science, 5 (4) (1994), pp. 502-527

H. Mintzberg. The Nature of Managerial Work. Harper and Row, New York (1973)

B. Nardi, S. Whittaker, E. Bradner. Interaction and outeraction: instant messaging in action. Proceedings of the 2000 ACM Conference on Computer Supported Cooperative Work (December, 2000)

R. Otando, J. Van Scotter, D. Allen, P. Palvia. The complexity of richness: media, message, and communication outcomes. Information \& Management, 45 (2008), pp. 21-30

S.R. Phillips, E.M. Eisenberg. Strategic uses of electronic mails in organizations. The Public, 3 (4) (1996), pp. 67-81

M. Porter, V.E. Millar. How information gives you competitive advantage. Harvard Business Review, 63 (4) (1985), pp. 149-160

R.E. Rice. Task analyzability, use of new media, and effectiveness: a multi-site exploration of media richness. Organization Science, 3 (4) (1992), pp. 475-500

R.E. Rice, U. Gattiker. New media and organizational structuring. F.M. Jablin, L.L. Putnam (Eds.), The New Handbook of Organizational Communication, Sage, Thousand Oaks, CA (2001), pp. 554-581

C.T. Romm, N. Pliskin, W.D. Rifkin. Diffusion of E-mail: an organisational learning perspective. Information \& Management, 31 (1) (October 1996), pp. 37-46

G.S. Russ, R. Daft, R. Lengel. Media selection and managerial characteristics. Management Communication Quarterly, 4 (2) (1990), pp. 151-175

S. Salmon, T. Joiner. Toward an understanding communication channel preference for the receipt of management information. The Journal of American Academy of Business, 7 (2) (2005), pp. 56-62

P. Shachaf, N. Hara. Behavioral complexity theory of media selection: a proposed theory for global virtual teams. Journal of Information Science, 33 (1) (2007), pp. 63-75 
C. Sia, B. Tan, K. Wei. Group polarization and computer-mediated communication: effects of communication cues, social presence, and anonymity. Information Systems Research, 13 (1) (2002), pp. 70-90

D. Straub, E. Karahanna. Knowledge worker communications and recipient availability: toward a task closure explanation of media choice. Organization Science, 9 (2) (1998), pp. 160-175

S. Sussman, L. Sproull. Straight talk: delivering bad news through electronic communication. Information Systems Research, 10 (2) (1999), pp. 150-166

D. Te'eni. Review: a cognitive-affective model of organizational communication for designing IT. MIS Quarterly, 25 (2) (2001), pp. 251-312

S. Thatcher, S. Brown. Individual creativity in teams: the importance of communication media mix. Decision Support Systems, 49 (2010), pp. 290-300

L. Treviño, J. Webster, E. Stein. Making connections: complementary influences on communication media choices, attitudes, and use. Organization Science, 11 (2) (2000), pp. 163182

L. Treviño, R. Lengel, R.L. Daft. Media symbolism, media richness, and media choice in organizations: a symbolic interactionist perspective. Communication Research, 14 (5) (1987), pp. 553-574

S.R. Vallabhaneni. Auditing Computer SecurityJohn Wiley \& Sons, Inc, New York, NY (1989)

J.B. Walther. Computer-mediated communication: impersonal, interpersonal and hyper-personal interaction. Communication Research, 23 (1) (1996), pp. 3-43

M. Walton. Liability@work: What's Your Corporate E-mail Policy? (April 24, 2000)

(TechRepublic.com (April 24, 2000), accessed at http://articles.techrepublic.com.com/510010878_11-1060911.html.)

M. Watson-Manheim, F. Belanger. Communication media repertoires: dealing with the multiplicity of media choices. MIS Quarterly, 31 (2) (2007), pp. 267-293

S. Whittaker, C. Sidner. Email overload: exploring personal information management of email. Proceedings of the SIGCHI Conference on Human Factors in Computing Systems, Vancouver, British Columbia, Canada (1996), pp. 276-283

R. Zmud, M. Lind, F. Young. An attribute space for organizational communication channels. Information Systems Research, 1 (4) (1990), pp. 440-457 